Research Paper

\title{
Which Adverse Events Are Related to Health Care during Hospitalization in Elderly Inpatients?
}

\author{
Julie Dupouy ${ }^{1,2,3,4}{ }^{\bowtie}$, Guillaume Moulis ${ }^{1,2,4}$, Marie Tubery${ }^{1}$, Marie Ecoiffier ${ }^{1}$, Agnès Sommet 2,4,5, \\ Jean-Christophe Poutrain 3, Philippe Arlet1,3, Maryse Lapeyre-Mestre2,4,5 \\ 1. CHU Toulouse, Service de Post-Urgences Médicales/Médecine Interne, place du Docteur Baylac, 31079 Toulouse, Cedex 9, France, \\ 2. UMR 1027 INSERM-Université de Toulouse, Faculté de Médecine, 37 allées Jules Guesde, 31062 Toulouse, France, \\ 3. Département Universitaire de Médecine Générale, 133 route de Narbonne, 31062 Toulouse, France, \\ 4. Université de Toulouse III, 118 route de Narbonne, 31062 Toulouse, Cedex 9, France \\ 5. CHU Toulouse, Service de Pharmacologie Clinique, Centre Midi-Pyrénées de PharmacoVigilance, de Pharmacoépidémiologie et \\ d’Informations sur le Médicament, Faculté de Médecine, 37 allées Jules Guesde, 31000 Toulouse, France
}

$\square$ Corresponding author: Julie Dupouy, MD, UMR 1027 INSERM-Université de Toulouse, Faculté de Médecine, 37 allées Jules Guesde, 31062 Toulouse, France. Tel. +33 5611459 18; Fax +33 5611459 28; E-mail: julie.dupouy@univ-tlse3.fr

( ) Ivyspring International Publisher. This is an open-access article distributed under the terms of the Creative Commons License (http://creativecommons.org/ licenses/by-nc-nd/3.0/). Reproduction is permitted for personal, noncommercial use, provided that the article is in whole, unmodified, and properly cited.

Received: 2013.05.07; Accepted: 2013.07.22; Published: 2013.07.3।

\begin{abstract}
Background: Adverse events result in longer hospital stays and increase costs and mortality. We aimed to assess incidence of adverse events occurring during hospitalization in a post-emergency unit and to describe their characteristics.

Methods: All adverse events occurring in patients during their hospitalization in a post-emergency unit in a French university hospital ( 20 beds) were systematically and consecutively recorded from September 2009 to February 20l I. Patients with adverse events were compared to up to three control patients, matched for date of admission $+/$ - age in the same unit.

Results: We identified 56 patients with 64 adverse events, giving an incidence of 3.0/100 patients admitted/year. Fifty-one adverse events were drug-related. Patients had a median age of 82.5 years with a male/female ratio of I/I.4. They presented a median Charlson score of I and the median number of medications was 6 . The drugs most frequently involved in drug-related events were nervous system drugs (47\%) and anti-infectives (22\%). In multivariate analysis, a Charlson score $\geq$ 2 was associated with the occurrence of adverse events (OR $0.4 ; 95 \% \mathrm{Cl}[0.2 \mathrm{I}-0.80]$ ).

Conclusions: Systematic recording showed that adverse events were not rare in a post-emergency unit. Patients with comorbid conditions were less likely to present an adverse event, possibly because of greater precautions taken by the medical team.
\end{abstract}

Key words: Adverse event, inpatients, hospitalization, pharmacovigilance, internal Medicine

\section{Introduction}

Adverse events occurring during hospitalization increase duration of hospital stay, costs and mortality (1-3). Prospective studies assessing hospital adverse events are sparse and were mostly conducted in intensive care units (2-4). As a result, a lot needs to be learned still in this field, such as incidence and characteristics of adverse events occurring in medical departments during hospitalization. Studies aiming to identify factors associated with the occurrence of hospital adverse events are rare (4-6), as are those dealing with device-related adverse events in medical departments.

Through systematic recording of all adverse events occurring in a post-emergency unit, our primary aim was to assess incidence of adverse events occurring during hospitalization; our secondary aim 
was to describe their characteristics and to determine their associated factors.

\section{Patients and methods}

We described adverse events, be they device-related or drug-related, occurring in the post-emergency unit at Toulouse university hospital, France, during hospitalization from September 1, 2009 to February 28, 2011.

Toulouse university hospital with 2840 beds was the $4^{\text {th }}$ French hospital in 2010. During the period of the study, there were 20 beds in post-emergency unit of Toulouse university hospital with a total of 1250 hospitalizations in 2010. Post-emergency unit is an acute care and medical short-stay ward which only accepts patients coming from emergencies. The aim of this ward is to dispose every day of downstream beds for emergencies. One characteristic of this unit is the short length of hospital stay (mean: 5 days in 2010). Patients requiring specialized care follow-up are quickly transferred to specialized care if necessary (rare cases: 118 transfers in 2010) or are addressed in an outpatient follow-up or in a later programmed hospitalization. Most of patients can go back to the place they leaved before (frequent cases: 1000 in 2010). Post-emergency unit accepts adult patients without age limit but, since its creation, mean age is over 80 years since direct hospitalization in geriatric units is quite difficult.

\section{Prospective identification of adverse events by physicians}

All adverse events occurring in the post-emergency unit are recorded in a dedicated file in the medical information systems program database (Programme de Médicalisation des Systèmes d'Information, PMSI). PMSI is a generalized hospital database in which medical data related to hospitalizations are entered. Each hospitalization corresponded to one file card in the PMSI, which means that the number of patients recorded in the PSMI corresponds to the number of patients admitted to the hospital. These data are used in the calculation of hospital funding and are now used for pharmaco-epidemiological studies to assess morbidity $(7,8)$.

In line with previous studies (9-13), we defined an adverse events as an event that i) was a source of harm to the patient, and ii) was due to medical management rather than to the disease process itself.

Since 2009, codes for extra and intra-hospital adverse events have been added in the PMSI database specifically for patients hospitalized in the post-emergency unit. Since that time, after discussion with the paramedical staff, senior physicians enter a prospective daily record of all adverse events that occur during hospitalization. They are searched during the daily morning staff for each in-hospital patient. A dedicated file is prospectively created to record all adverse events noted by physicians. Thus all patients presenting an adverse event identified by senior physicians working in the post-emergency unit were consecutively and prospectively recorded in the database. All the hospital adverse events codes recorded from September 1, 2009 to February 28, 2011 were included.

\section{Data analysis}

\section{Data collection}

According to the list of patients provided by the database, we performed a retrospective data collection among medical files to complete reports and outcomes of these adverse events. Two independent investigators reviewed the corresponding medical files to check that the adverse events occurred during hospitalization. Data collected were age, sex, number of medications, comorbidities, dependency, history of hospitalization and type of adverse events. The number of drugs at admission included both chronic and acute treatments. Comorbidities were assessed by the Charlson score (14). Dependency was defined as need for nursing care at home or living in a care home or institution before admission.

\section{Definitions of adverse events}

The primary aim was to assess incidence of adverse events occurring during hospitalization. Adverse events were classified between device-related events and drug-related events by the two independent investigators. Device-related events were defined like having technical causes. Drug-related events were defined like any untoward medical occurrence that may present itself during treatment with a medicine but which does not necessarily have a causal relationship with the treatment (15).

\section{Case-control study}

To identify associated factors, patients with adverse events were compared to up to 3 control patients matched for date of admission +/- age, hospitalized in the same unit. The only criterion for eligibility of controls was they were hospitalized on the same day of case. If there were more than three patients admitted during a day, we chose the three patients nearer in age. If there were less to three patients admitted during a day, we could not find three matches and so patient was compared to one or two matches. If a case was the only patient admitted during a day, he/she was excluded from analysis as they could not be matched with controls. If several adverse events occurred in the same patient, only the first was 
considered for this part of analysis.

\section{Statistical analysis}

The sample size was based on the feasibility of data collection and was considered sufficient to observe an incidence of $10 \%$ of adverse event occurring during hospitalization (9).

To compare cases and controls, the $\chi^{2}$ test or Fisher test was performed for qualitative variables and the Wilcoxon test for quantitative variables. To identify factors associated with the occurrence of adverse events, be they drug-related or device-related, a conditional logistic regression was performed. Covariates associated at the threshold of $20 \%$ were included in the multivariate model (backward procedure, $a=5 \%)$. Variables included in the model were age, sex, number of drugs, Charlson score, dependency and hospitalization in the previous year. As we wanted to know associated factors with adverse events, backward procedure was chosen. The goodness-of-fit of the regression model was assessed by Hosmer-Lemeshow test for adequacy and area under the curve for discriminating power. Statistical analyses were performed with SAS 9.2 ${ }^{\circledR}$ software (SAS Inst., Cary, NC, USA).

\section{Results}

Among 1842 patients admitted to the post-emergency unit from September 1, 2009 to February 28, 2011, 75 patients were encoded for hospital adverse events. Nineteen patients were excluded: 7 because they presented extra-hospital adverse events and 12 because they were wrongly coded and had no adverse events (Fig. 1). Finally, 56 patients were included, presenting 64 hospital adverse events (5 patients presented 2 adverse events and one experienced $4)$. Ten patients experienced only device-related events and 46 experienced drug-related events.

In the post-emergency unit, the incidence of hospital adverse events was 3.0/100 patients admitted/year [95\% CI: 2.0-4.1]. Adverse events occurred in the first days of hospitalization at a median of 2 days [Q1-Q3: 1-3].

Patients had a median age of 82.5 years [Q1-Q3: 72-86.5], 33 (51.6\%) were women. Twenty seven $(48.2 \%)$ were dependent, $12(21.4 \%)$ had been hospitalized in the previous year. They were receiving a median of 6 medications [Q1-Q3: 3-8] and had a median Charlson score of 1 [Q1-Q3: 0-3]. Median length of hospital stay was 6.5 days [Q1-Q3: 4-8].

Of the 64 hospital adverse events, 13 were device-related events and 51 were drug-related.

\section{Device-related events $(n=13)$}

Device-related events were vascular in 6 cases: 5 related to peripheral catheters (3 cases of veinitis, 1 edema after perfusion, 1 contrast product extravasation) and 1 phlebitis, while 3 were urological ( 3 hematurias and 1 urinary infection post-catheterization), 3 were traumatological ( 2 falls and 1 humeral fracture after physical contention) and 1 was a post-lumbar puncture headache.



Figure I. Flowchart illustrating the patient selection process in the post-emergency unit of Toulouse university hospital. PMSI Programme de Médicalisation des Systèmes d'Information Médicale, medical information systems program database. 


\section{Drug-related events $(n=5 I)$}

The drugs most frequently involved in drug-related events were those targeting the nervous system $(47.4 \%)$ and anti-infectives (21.8\%) (Table 1$)$. Nervous system drugs caused neurological disorders such as drowsiness (7 events), digestive disorders such as vomiting (5 events) and traumatic injuries (2 falls). Anti-infectives caused skin reactions (4 rashes), fever ( 3 events) and hepatitis ( 2 events) (Table 2 ).

\section{Cases $(n=52,10$ patients with device-related events and 42 patients with drug-related events) and controls $(n=I \mid 8)$}

Four patients were the only patients to be hospitalized on a day and could not be matched with controls. These patients were patients with drug-related events. Thus, 52 cases were matched to 118 controls (mean of 2.3 controls per case). The characteristics of cases and controls are reported in Table 3. Patients with adverse events had a lower Charlson score $(\mathrm{p}=0.02)$ and a longer hospital stay $(\mathrm{p}$ $=0.007$ ). Charlson comorbid conditions (with weights) present at admission for patients included in the conditional logistic regression are presented in Table 4. In univariate analysis, factors associated with the occurrence of hospital adverse events were the number of drugs at admission $(p=0.2)$ and the Charlson score $(p=0.01)$ (Table 5). In multivariate analysis, a high Charlson score was the only factor associated with adverse events (OR 0.41; 95\% confidence interval $[0.21-0.80])$. Model was adequate (Hosmer-Lemeshow test $p=1$ ) and discriminating powerful (area under the curve $\mathrm{c}=0.63$ ).
Table I Drugs related to adverse events according to anatomical therapeutic chemical class.

\begin{tabular}{lll}
\hline Drug classes & $\mathrm{n}$ & $\%$ \\
\hline N Nervous system & $\mathbf{3 7}$ & $\mathbf{4 7 . 4}$ \\
N02 Analgesics & 13 & 16.7 \\
N03 Antiepileptics & 4 & 5.1 \\
N05 Psycholeptics & 17 & 21.8 \\
N06 Psychoanaleptics & 3 & 3.9 \\
J Anti-infectives for systemic use & $\mathbf{1 7}$ & $\mathbf{2 1 . 8}$ \\
J01 Antibacterials for systemic use & 16 & 20.5 \\
J05 Antivirals for systemic use & 1 & 1.3 \\
C Cardiovascular system & $\mathbf{8}$ & $\mathbf{1 0 . 3}$ \\
C01 Cardiac therapy & 3 & 3.9 \\
C03 Diuretics & 2 & 2.6 \\
C07 Beta blocking agents & 2 & 2.6 \\
C09 Agents acting on the renin-angiotensin system & 1 & 1.3 \\
B Blood and blood forming organs & $\mathbf{6}$ & $\mathbf{7 . 7}$ \\
B01 Antithrombotic agents & 5 & 6.4 \\
B05 Blood substitutes and perfusion solutions & 1 & 1.3 \\
H Systemic hormonal preparations, excl. sex hormones & $\mathbf{5}$ & $\mathbf{6 . 4}$ \\
and insulin & & \\
H02 Corticosteroids for systemic use & 5 & 6.4 \\
M Musculoskeletal system & $\mathbf{2}$ & $\mathbf{2 . 6}$ \\
M01Antiinflammatory and antirheumatic products & 1 & 1.3 \\
M03 Muscle relaxants & 1 & 1.3 \\
A Alimentary tract and metabolism & $\mathbf{1}$ & $\mathbf{1 . 3}$ \\
A10 Drugs used in diabetes & 1 & 1.3 \\
P Antiparasitic products, insectisides and repellents & $\mathbf{1}$ & $\mathbf{1 . 3}$ \\
P01 Antiprotozoals & 1 & 1.3 \\
R Respiratory system & $\mathbf{1}$ & $\mathbf{1 . 3}$ \\
R03 Drugs for obstructive airway diseases & 1 & 1.3 \\
\hline & & \\
& &
\end{tabular}

Table 2 Description of drug-related events and drugs involved.

\begin{tabular}{|c|c|c|}
\hline Drug-related events & $\begin{array}{l}\text { Number of } \\
\text { occurrences }\end{array}$ & Drugs (number of times drug was involved) \\
\hline $\begin{array}{l}\text { Neurological disorders (drowsiness, dizziness, } \\
\text { hallucinations, somnolence, etc.) }\end{array}$ & 17 & $\begin{array}{l}\text { Psycholeptics (13), Analgesics (5), Antiepileptics (2), Psychoanaleptics (2), } \\
\text { Antibacterials (2), Antivirals (1), Corticosteroids (1), Beta blocking agents (1) }\end{array}$ \\
\hline Gastrointestinal disorders (diarrhea, nausea) & 7 & Analgesics (5), Antiepileptics (1), Antibacterials (1), Muscle relaxants (1) \\
\hline $\begin{array}{l}\text { Metabolic disorders (hypokalemia, hypo- } \\
\text { natremia, hypo or hyperglycemia) }\end{array}$ & 6 & $\begin{array}{l}\text { Corticosteroids (4), Diuretics (1), Beta Blocking agents (1), Blood substitutes } \\
\text { and perfusion solution (1), Drugs used in diabetes (1), Antibacterials (1), } \\
\text { Drugs for obstructive airway diseases (1) }\end{array}$ \\
\hline Skin reactions (rash, urticaria, pruritus, etc.) & 6 & Antibacterials (5), Analgesics (2), Antiprotozoals (1) \\
\hline $\begin{array}{l}\text { Urinary disorders (acute urinary retention, he- } \\
\text { maturia) }\end{array}$ & 4 & Antithrombotic agents (5), Antibacterials (1), Analgesics (1) \\
\hline Fever & 3 & Antibacterials (3) \\
\hline Hepatic reactions & 3 & Antibacterials (3), Psychoanaleptics (1) \\
\hline $\begin{array}{l}\text { Cardiovascular disorders (bradycardia, atrial } \\
\text { fibrillation) }\end{array}$ & 2 & Cardiac therapy (3) \\
\hline Falls & 2 & $\begin{array}{l}\text { Psycholeptics (4), Antiepileptics (1), Diuretics (1), Agents acting on the ren- } \\
\text { in-angiotensin system (1) }\end{array}$ \\
\hline Renal failure & 1 & Antiinflammatory and rheumatic products (1) \\
\hline
\end{tabular}


Table 3 Characteristics of cases and controls, $n=\mid 70$.

\begin{tabular}{llll}
\hline & Cases & Controls & p value \\
& $\mathrm{n}=52$ & $67(56.8)$ & 0.7 \\
\hline Women n (\%) & $28(53.8)$ & $82.5[75-88]$ & 0.6 \\
Age, years, median, [Q1-Q3] & $82[72-86]$ & $66(55.9)$ & 0.4 \\
Dependency n (\%) & $25(48.1)$ & $32(27.1)$ & 0.4 \\
Hospitalization in the previous year n (\%) & $10(19.2)$ & $7[4-9]$ & 0.1 \\
Number of drugs median, [Q1-Q3] & $6[3-8]$ & $2[1-3]$ & 0.02 \\
Charlson score median, [Q1-Q3] & $1[0-3]$ & $5[3-6]$ & 0.007 \\
Length of hospital stay, days, median, [Q1-Q3] & $6.5[4-8]$ & & \\
\hline
\end{tabular}

Q1, first quartile; Q3 third quartile

Table 4 Charlson comorbid conditions (with weights) present at admission for all patients included in the conditional logistic regression.

\begin{tabular}{lllll}
\hline Charlson comorbid conditions & Weight & $\begin{array}{l}\text { No (\%) of pa- } \\
\text { tients } \\
\mathrm{n}=170\end{array}$ & $\begin{array}{l}\text { No (\%) of cases } \\
\mathrm{n}=52\end{array}$ & $\begin{array}{l}\text { No (\%) of con- } \\
\text { trols } \\
\mathrm{n}=118\end{array}$ \\
\hline Myocardial infarction & 1 & $26(15.3)$ & $8(15.4)$ & $18(15.3)$ \\
Congestive cardiac failure & 1 & $39(22.9)$ & $11(21.2)$ & $28(23.7)$ \\
Peripheral vascular disease & 1 & $27(15.9)$ & $4(7.7)$ & $23(19.5)$ \\
Cerebrovascular disease & 1 & $20(11.8)$ & $9(17.3)$ & $11(9.3)$ \\
Dementia & 1 & $38(22.4)$ & $10(19.2)$ & $28(23.7)$ \\
Chronic pulmonary disease & 1 & $25(14.7)$ & $7(13.5)$ & $18(15.3)$ \\
Rheumatological disease & 1 & $8(4.7)$ & $0(0.0)$ & $8(6.8)$ \\
Peptic ulcer disease & 1 & $8(4.7)$ & $1(1.9)$ & $7(5.9)$ \\
Mild liver disease & 1 & $5(2.9)$ & $0(0.0)$ & $5(4.2)$ \\
Diabetes (mild to moderate) & 1 & $30(17.7)$ & $6(11.5)$ & $24(20.3)$ \\
Diabetes with complications & 2 & $7(4.1)$ & $3(5.8)$ & $4(3.4)$ \\
Hemiplegia or paraplegia & 2 & $3(1.8)$ & $1(1.9)$ & $2(1.7)$ \\
Renal disease & 2 & $14(8.2)$ & $1(1.9)$ & $13(11.0)$ \\
Any malignancy, including lymphoma/leukemia & 2 & $32(18.8)$ & $9(17.3)$ & $23(19.5)$ \\
Moderate or severe liver disease & 3 & $2(1.2)$ & $1(0.9)$ & $1(1.9)$ \\
Metastatic solid tumor & 6 & $4(2.4)$ & $0(0.0)$ & $4(3.4)$ \\
Acquired immunodeficiency syndrome AIDS & 6 & $0(0.0)$ & $0(0.0)$
\end{tabular}

Table 5 Factors associated with occurrence of intra hospital adverse events *.

\begin{tabular}{|c|c|c|c|c|}
\hline & Univariate analysis & & Multivariate ana & \\
\hline & OR $[95 \% \mathrm{CI}]$ & $\mathrm{p}$ value & OR $[95 \% \mathrm{CI}]$ & $\mathrm{p}$ value \\
\hline Women & $0.97[0.48-1.95]$ & 0.9 & - & - \\
\hline $\begin{array}{l}\text { Age } \geq 80 \text { year } \\
\text { (versus }<80 \text { year) }\end{array}$ & $1.14[0.56-2.29]$ & 0.7 & - & - \\
\hline Dependency & 0.69 [0.34-1.39] & 0.3 & - & - \\
\hline Hospitalization in the previous year & $0.66[0.29-1.50]$ & 0.3 & - & - \\
\hline $\begin{array}{l}\text { Number of drugs } \geq 6 \\
\text { (versus }<6 \text { ) }\end{array}$ & $0.62[0.31-1.24]$ & 0.2 & - & - \\
\hline Charlson score $\geq 2$ (versus < 2) & $0.42[0.22-0.83]$ & 0.01 & $0.41[0.21-0.80]$ & 0.009 \\
\hline
\end{tabular}

OR, odds ratio; $95 \% \mathrm{CI}$, confidence interval at $95 \%$.

*Variables initially included in the model were age, sex, number of drugs, Charlson score, dependency, hospitalization in the previous year. 


\section{Discussion}

The incidence of hospital adverse events was 3.0/100 patients admitted/year, consistent with findings of previous studies. The prevalence of adverse events in medical departments has been estimated at from 3 to $17 \%$ (3.7\% in New York hospitals (13), $8.4 \%$ in Spanish hospitals (16), 10.5\% in the hospitals of five Latin American countries (17), 12.2\% in Canadian hospitals (18) and up to $16.6 \%$ in Australia (12)). These discrepancies may be explained by different definitions of adverse events (16). A strength of our study is that it was prospective, thus enabling us to estimate the incidence of hospital adverse events. This is similar to the incidence density previously identified in French national surveys $(9,19)$.

Most adverse events were drug-related. We cannot exclude the possibility that device-related events were under-recorded because they appeared less serious. However, the recording method, based on daily discussion between medical and paramedical staff, should allow identification of device-related events. Device-related events have been closely studied in anesthetic and surgical wards (9) but have not been precisely described in medical wards.

Drugs involved in hospital drug-related events were predominantly nervous system drugs followed by anti-infectives. These results are similar to those of another study in a post-emergency unit (6), but are in contrast with the systematic review of Cano et al., who found that anti-infectives were the drugs most often involved (20). This discrepancy is probably due to the characteristics of patients in the post-emergency unit, who are older and have fewer infections than patients from intensive care units such as those included in the review of Cano et al. In the prospective study of Lagnaoui et al. (21), neurological disorders were the most frequent adverse drug reactions occurring in a French internal medicine department.

In the multivariate model, only the Charlson score was associated with the occurrence of adverse events. In the literature, factors associated with the occurrence of adverse events were female sex $(22,23)$, number of drugs $(5,6,24,25)$, comorbidities, dependency $(5,6,24)$, lower weight, and smoking history with concurrent diseases (4). In our study, lack of power and overmatching cannot be excluded. Selection bias we discussed above cannot be excluded too. Matching on admission date was justified to take into account the lack of medical and paramedical staff during weekends, which could be an important confounder for adverse events occurrence. In our study, inpatients with comorbid conditions were less likely to present an adverse event during their hospitalization in the post-emergency unit. This unexpected result should be compared with the findings of Zhang et al. (26), who assessed factors associated with repeat admission to hospital for adverse drug reactions in older adults: the Charlson score was a risk factor for repeat admission, while certain Charlson comorbid conditions taken into consideration independently were protective for repeat admission. These comorbid conditions were cerebrovascular disease, dementia and hemiplegia or paraplegia. In our population, we observed the same range of comorbid conditions: $11.8 \%$ for cerebrovascular disease, $22.9 \%$ for dementia and $1.8 \%$ for hemiplegia or paraplegia (versus $6.4 \%$ for cerebrovascular disease, $3.0 \%$ for dementia and 3.0\% for hemiplegia or paraplegia in the study of Zhang et al.). These could have influenced the global association with the Charlson score. This could be explained by a differential bias in care, as the medical and paramedical teams may have taken more precautions with frail patients.

The incidence of hospital adverse events was 3.0/100 patients admitted/year in our post-emergency unit. Most adverse events were drug-related. The majority of the drugs involved in drug-related events were nervous system drugs. In this survey, inpatients with comorbid conditions were less likely to present adverse events, possibly because of greater precautions taken by the medical team.

\section{Acknowledgments}

The authors would like to thank Nina Crowte for her help in correcting the English text.

\section{Competing Interests}

The authors have declared that no competing interest exists.

\section{References}

1. Classen DC, Pestotnik SL, Evans RS, Lloyd JF, Burke JP. Adverse drug events in hospitalized patients. Excess length of stay, extra costs, and attributable mortality. JAMA. 1997; 277(4): 301-306.

2. Forster AJ, Kyeremanteng $\mathrm{K}$, Hooper J, Shojania KG, van Walraven C. The impact of adverse events in the intensive care unit on hospital mortality and length of stay. BMC Health Serv Res. 2008; 8: 259.

3. Kaushal R, Bates DW, Franz C, Soukup JR, Rothschild JM. Costs of adverse events in intensive care units. Crit. Care Med. 2007; 35(11): 2479-2483.

4. Mohebbi N, Shalviri G, Salarifar M, Salamzadeh J, Gholami K. Adverse drug reactions induced by cardiovascular drugs in cardiovascular care unit patients. Pharmacoepidemiol Drug Saf. 2010; 19(9): 889-894.

5. Madeira S, Melo M, Porto J, Monteiro S, Pereira de Moura JM, Alexandrino MB, et al. The diseases we cause: Iatrogenic illness in a department of internal medicine. Eur J Intern Med. 2007; 18(5): 391-399.

6. Fauchais A-L, Ploquin I, Ly K, Rhaïem K, Bezanahary H, Tarnaud T, et al. [Adverse drug related events in a postemergency unit: prospective cohort study with 6 months follow up]. Rev Med Interne. 2006; 27(5): 375-381.

7. Lugardon S, Desboeuf K, Fernet P, Montastruc J-L, Lapeyre-Mestre M. Using a capture-recapture method to assess the frequency of adverse drug reactions in a French university hospital. Br J Clin Pharmacol. 2006; 62(2): 225-231.

8. Jouanjus E, Pourcel L, Saivin S, Molinier L, Lapeyre-Mestre M. Use of multiple sources and capture-recapture method to estimate the fre- 
quency of hospitalizations related to drug abuse. Pharmacoepidemiology and drug safety. 2012; 21(7): 733-741.

9. Michel P, Quenon JL, Djihoud A, Tricaud-Vialle S, de Sarasqueta AM. French national survey of inpatient adverse events prospectively assessed with ward staff. Qual Saf Health Care. 2007; 16(5): 369-377.

10. Vincent C, Neale G, Woloshynowych M. Adverse events in British hospitals: preliminary retrospective record review. BMJ. 2001; 322(7285): 517-519.

11. Davis P, Lay-Yee R, Briant R, Scott A. Preventable in-hospital medical injury under the «no fault » system in New Zealand. Qual Saf Health Care. 2003; 12(4): 251-256.

12. Wilson RM, Runciman WB, Gibberd RW, Harrison BT, Newby L, Hamilton JD. The Quality in Australian Health Care Study. Med J Aust. 1995; 163(9): 458-471.

13. Brennan TA, Leape LL, Laird NM, Hebert L, Localio AR, Lawthers AG, et al. Incidence of adverse events and negligence in hospitalized patients: results of the Harvard Medical Practice Study I. 1991. Qual Saf Health Care. 2004; 13(2): 145-151; discussion 151-152.

14. Charlson ME, Pompei P, Ales KL, MacKenzie CR. A new method of classifying prognostic comorbidity in longitudinal studies: development and validation. J Chronic Dis. 1987; 40(5): 373-383.

15. World Health Organization Collaborating Center for International Drug Monitoring. The importance of pharmacovigilance. Safety monitoring of medicinal products. Geneva: World Health Organization; 2002.

16. Aranaz-Andrés JM, Aibar-Remón C, Vitaller-Murillo J, Ruiz-López P, Limón-Ramírez R, Terol-García E. Incidence of adverse events related to health care in Spain: results of the Spanish National Study of Adverse Events. J Epidemiol Community Health. 2008; 62(12): 1022-1029.

17. Aranaz-Andrés JM, Aibar-Remón C, Limón-Ramírez R, Amarilla A, Restrepo FR, Urroz O, et al. Prevalence of adverse events in the hospitals of five Latin American countries: results of the «Iberoamerican study of adverse events » (IBEAS). BMJ Qual Saf. 2011; 20(12): 1043-51

18. Baker GR, Norton PG, Flintoft V, Blais R, Brown A, Cox J, et al. The Canadian Adverse Events Study: the incidence of adverse events among hospital patients in Canada. CMAJ. 2004; 170(11): 1678-1686.

19. [Internet] Michel P, Lathelize M., Bru-Sonnet R, Domecq S, Kret M, Quenon JL. Enquête Nationale sur les Evénements Indésirables graves liés aux Soins 2009 (ENEIS2) : description des résultats 2009; Rapport final à la DREES (Ministère du travail, de l'emploi et de la Santé). http://www.ccecqa.asso.fr/sites/ccecqa.cpm.aquisante.priv/files/ENE IS-RapportFinal2009-Mars2011.pdf

20. Cano FG, Rozenfeld S. Adverse drug events in hospitals: a systematic review. Cad Saude Publica. 2009; 25 Suppl 3: S360-372.

21. Lagnaoui R, Moore N, Fach J, Longy-Boursier M, Bégaud B. Adverse drug reactions in a department of systemic diseases-oriented internal medicine: prevalence, incidence, direct costs and avoidability. Eur J Clin Pharmacol. 2000; 56(2): 181-186.

22. Zopf Y, Rabe C, Neubert A, Hahn EG, Dormann H. Risk factors associated with adverse drug reactions following hospital admission: a prospective analysis of 907 patients in two German university hospitals. Drug Saf. 2008; 31(9): 789-798.

23. Zopf Y, Rabe C, Neubert A, Gassmann KG, Rascher W, Hahn EG, et al. Women encounter ADRs more often than do men. Eur J Clin Pharmacol. 2008; 64(10): 999-1004.

24. Cecile M, Seux V, Pauly V, Tassy S, Reynaud-Levy O, Dalco O, et al. [Adverse drug events in hospitalized elderly patients in a geriatric medicine unit: study of prevalence and risk factors]. Rev Med Interne. 2009; 30(5): 393-400.

25. Davies EC, Green CF, Taylor S, Williamson PR, Mottram DR, Pirmohamed M. Adverse drug reactions in hospital in-patients: a prospective analysis of 3695 patient-episodes. PLoS ONE. 2009; 4(2): e4439.

26. Zhang M, Holman CDJ, Price SD, Sanfilippo FM, Preen DB, Bulsara MK. Comorbidity and repeat admission to hospital for adverse drug reactions in older adults: retrospective cohort study. BMJ. 2009; 338: a2752. 